\title{
Security Assessment of Distribution System with Distributed Photovoltaic
}

\author{
Weiping Zhu1, Zhicheng Wang2, Xiaodong Yuan', Ruonan Fan ${ }^{3 *}$ \\ ${ }^{1}$ Jiangsu Electric Power Company Research Institute, Jiangsu, China \\ ${ }^{2}$ State Grid Jiangsu Electric Power Company, Jiangsu, China \\ ${ }^{3}$ Photovoltaic System Research Center of Ministry of Education, Hefei University of Technology, Hefei, China \\ Email: ${ }^{2} 25161943 @ q q . c o m$
}

Received January 2015

\begin{abstract}
In order to evaluate the safe and stable operation of distribution network with the distributed photovoltaic (PV), the security of distribution network is researched. On the basis of electricity supply security, voltage quality and network losses, the index system of static security is established. The paper simulates the uncertainty and random characteristics of PV by OpenDSS. The typical scenes that PV accessed to the distribution network are designed. The paper summarizes the results of voltage fluctuation and network losses and uses indices to quantify it under different scenes. Based on the index system, the paper proposes some recommendations on PV permeability, interconnected locations, dispersion degrees and power factors when the distributed PV accessed to the distribution network.
\end{abstract}

\section{Keywords}

Distributed PV, Static Security, Index System, Voltage Fluctuation, Network Losses

\section{Introduction}

In recent years, the proportion of PV generation in the power industry is increasing heavily. With the continuous development of large-scale grid-connected PV, the research on security of distribution network with distributed PV is becoming increasingly important. A large quantity of distributed PV accessed to the distribution network, transforms traditional signal power network into multiport grid and the direction of power flow becomes multiple. PV generation is volatile and has low density and self-adjustment abilities, its power generation is affected by temperature, irradiance and other factors. So the fluctuation and randomness of output power are large and have a significant impact on the safe operation of the distribution network. Therefore, it is important to research the security of the distribution network with modularized distributed PV.

At present, most security studies of distribution network with distributed PV are based on post-fault analyses. Reference [1] proposes some assessment indices based on the security rules of $K(N-1+1)$, and fuzzy comprehensive model is used to evaluate the safety; considering the risk theory, reference [2] proposes the risk indi-

*Corresponding author.

How to cite this paper: Zhu, W.P., Wang, Z.C., Yuan, X.D. and Fan, R.N. (2015) Security Assessment of Distribution System with Distributed Photovoltaic. Journal of Power and Energy Engineering, 3, 250-261.

http://dx.doi.org/10.4236/ipee.2015.34034 
cators of load losses, overload and voltage limit violation. The evaluations of operation process are too little to evaluate the influences of PV on distribution network and can't give advices for reasonable planning of power system. Reference [3] analyzes the impacts caused by grid-connected PV on distribution network voltages and losses in mechanism. The peak capacity of distributed PV source with constraint of over-voltage is researched in [4].

Firstly, the paper proposes an index system of static security assessment. The randomness of PV generation is simulated by OpenDSS. In addition, the typical scenes that PV accessed to the distribution network are designed to analyze the influences of network's normal operation ratio, voltage fluctuation and network losses under different capacities, interconnected locations, dispersion conditions and power factors of grid-connected PV. The voltage fluctuation indices and mitigation degree of network losses are calculated. Finally, to improve the safety and stability of distribution network and reduce the network losses, the paper proposes some advices on different conditions that PV accessed to the distribution network such as PV permeability and interconnected locations.

\section{Index System of Static Security Assessment}

Distribution network static security is used to judge whether the abnormal status occur under certain operation conditions, such as over voltage, lines and components overload [5]. The paper assesses the static security on the basis of electricity supply security, voltage quality and network losses.

Firstly, the normal operation ratio index is calculated. Ensure that the distribution network system is in normal operation condition and then evaluate the voltage quality and network losses by other indices. The grid-connected PV changes the power flow of distribution network, because of the reduction of feeder transmission power and the reactive power generated by PV, the node voltage will increase and the voltage fluctuation will change [6]. Thus this paper measures the voltage quality mainly from voltage fluctuation ratio. The active and reactive power of the line varies widely when different capacities, locations, dispersion degrees and power factors of PV which accessed to the distribution network. The network losses which mainly depend on system power flow will be affected inevitably by the access of PV [7]. The network losses indices include percentage of power losses and mitigation degree of network losses. The mitigation degree of network losses reflects the improvement levels of network losses under different access conditions [8]-[10].

The static security indices are shown as Figure 1 below.

\subsection{Normal Operation Ratio $E$}

Normal operation ratio $E$ is introduced for judging whether the feeder current exceeds the normal allowable current.

$$
E=\frac{I}{I_{N}} \times 100 \%
$$

where, $I$ is feeder current and $I_{N}$ is normal allowable current.

Too heavy loads of the distribution network will lead to the excessive current. It's easy to cause the overload phenomenon when the current exceeds the normal allowable value. Higher the value of $E$, more load demands

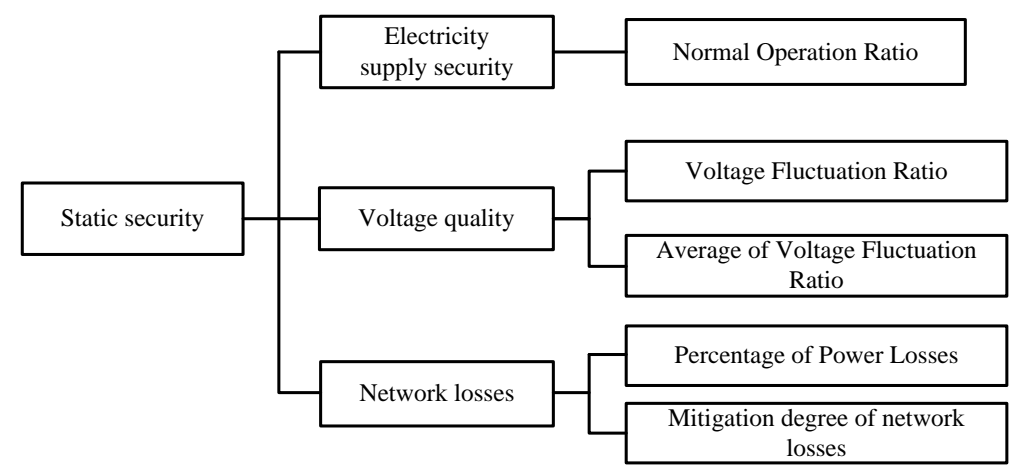

Figure 1. Index system of static security. 
the network meet.

\subsection{Voltage Fluctuation Ratio $\Delta V_{\%}$}

Voltage Fluctuation Ratio is introduced to study the effects of PV on voltage fluctuation.

$$
\Delta V_{\%}=\frac{\left|V_{a}(t)-V_{a}(t-1)\right|}{V_{a}(t-1)} \times 100 \%
$$

where, $V_{a}(t)$ and $V_{a}(t-1)$ are one node's voltage of adjacent time.

Voltage fluctuation ratio describes one node's voltage fluctuation levels for some time. The ratio is higher, the fluctuation is larger, and the stability of distribution network will have big changes.

\subsection{Average of Voltage Fluctuation Ratio $E_{\Delta V \%}$}

$$
E_{\Delta V \%}=\frac{1}{n} \sum_{1}^{n} \Delta V_{\%}
$$

The grid-connected PV has great influences on voltage fluctuation of distribution network, especially when PV puts into operation or breaks off from the network. The influences also depend on the capacities, locations, power factors of PV and topologies of distribution networks, the assessment of voltage fluctuation is more difficult. Thus the average of voltage fluctuation ratio is introduced to evaluate the overall levels of voltage fluctuation under different access situations.

\subsection{Percentage of Power Losses $P_{\text {loss }} \%$}

$$
P_{\text {loss }} \%=\frac{P_{\text {loss }}}{P}
$$

where, $P_{\text {loss }}$ is total losses and $\mathrm{P}$ is total load power.

\subsection{Mitigation Degree of Network Losses $M$}

$$
\mathrm{M}=\frac{W^{\prime}-W_{\mathrm{PV}}}{W^{\prime}}
$$

where, $W^{\prime}$ is total losses of distribution network without grid-connected PV, $W_{\mathrm{PV}}$ is total losses after PV accessed to the distribution network.

The value of $M$ is higher, the network losses is smaller. It indicated that grid-connected PV leads to better reduction of network losses.

\section{Models of Security Assessment Based on OpenDSS}

Facing with distribution network's functional requirements of fast simulation, American Electric Power Research Institute provides the OpenDSS software to support the design, planning, operation and research of distribution system. OpenDSS has a variety of network models, can realize fast and stable power flow calculation and shows the nice convergence property and fast calculation speed. It also applies to power flow calculation for large-scale distribution network. In addition, the user can realize further extending application and analysis through the COM interface. OpenDSS provides an open and sharing software platform for smart grid and plays an important role in the future development [11].

\subsection{Grid-Connected PV Model}

The dynamic meteorological parametersof PV model are irradiance $\left(I_{r r}\right)$ and panel temperature $(T)$, and the simulation uses daily mode to realize the random characteristic.

Figure 2 shows a schematic diagram of the PV system device model. 


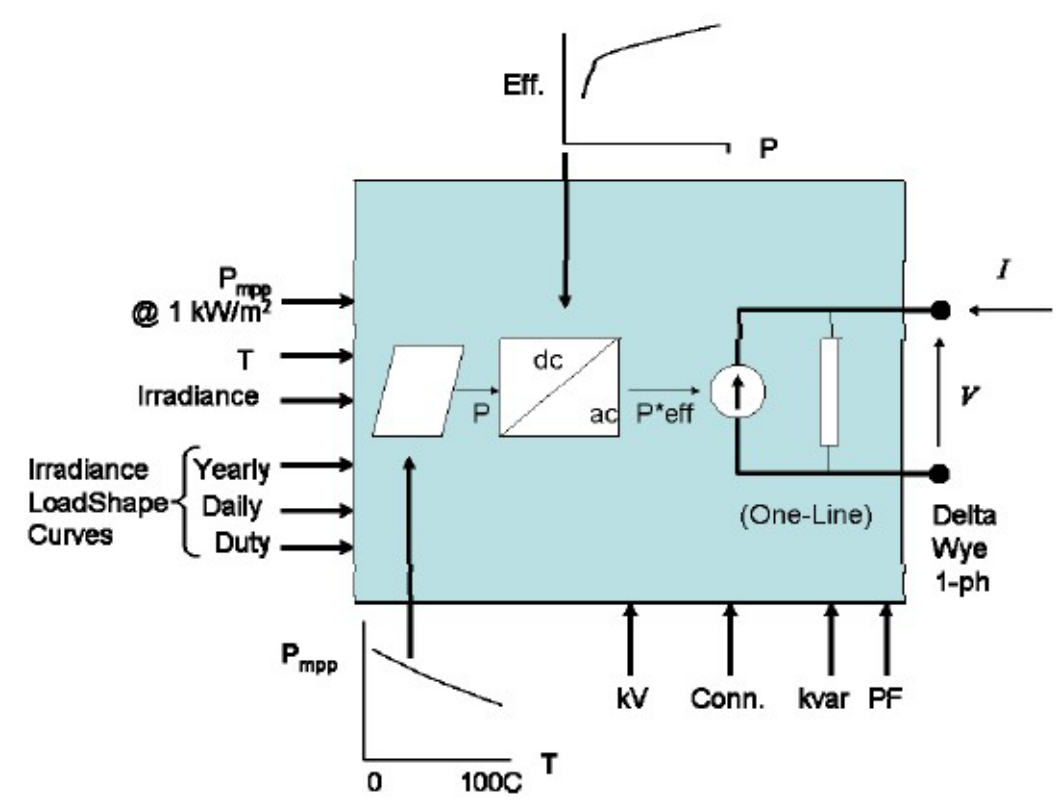

Figure 2. Schematic diagram of PV model.

The active power, $P$, is a function of the $I_{r r}, T$, and rated power at the mpp, $P_{\mathrm{mpp}}$ at a selected temperature and an irradiance of $1.0 \mathrm{KW} / \mathrm{m}^{2}$. The model assumes the inverter is able to find the max power point (mpp) of the panel quickly. Considering the losses of PV inverter, the model sets the efficiency factor for the inverter $\left(E_{\mathrm{FF}}\right)$. Define each temperature as well as its corresponding output power coefficient $F_{T}$ curve, according to the current temperature $\mathrm{T}$ to get output power coefficient $F_{T}$.

PV output power is calculated by formula (6).

$$
P_{n}=I_{r r} * P_{\mathrm{mpp}} * F_{T} * E_{\mathrm{FF}}
$$

Timing $I_{r r}$ and $T$ are selected to be the dynamic meteorological parameters of PV model on one day in the second quarter in a region.

\subsection{Model of Distribution Network}

In this paper, the simulation uses the actual distribution network structure of a certain region.

According to the radial chain distribution network structure, each concentrated load along the feeder will be seen as a node and be numbered. Considering the different types of transmission lines, which lead to the positive and zero sequence resistance, positive and zero sequence reactance, positive and zero sequence capacitance of lines and other parameters are different, the connection point of different types of transmission lines is also seen as a node. The substation in the beginning is signed as N1. The simplified distribution network model is shown in Figure 3.

Set the voltage of the beginning is $10.5 \mathrm{kV}$, the parameters of three-phase lines and loads are the actual data of a certain region. Assuming that the each phase impedance of lines and the each phase load of nodes are symmetrical, the random power flow is calculated on the basis of this system with PV added in.

\subsection{Scene of Grid-Connected PV}

The typical scenes that PV accessed to the network are designed in order to obtain the reasonable planning advices. On the one hand, considering the internal factors of PV, output power of PV system mainly depends on its capacity and power factor when the meteorological parameters arecertainty. On the other hand, considering the relationship between PV and distribution network, output power now mainly depends on interconnected locations and dispersion degrees.

The typical scenes are designed and as shown below (Figure 4). 


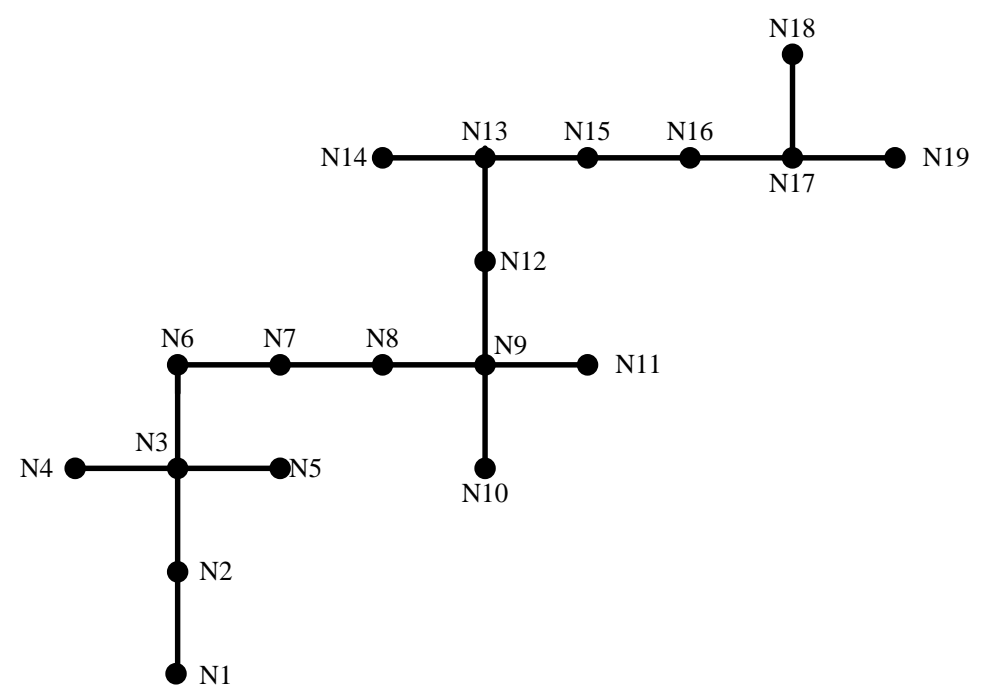

Figure 3. Simplified model of distribution network.

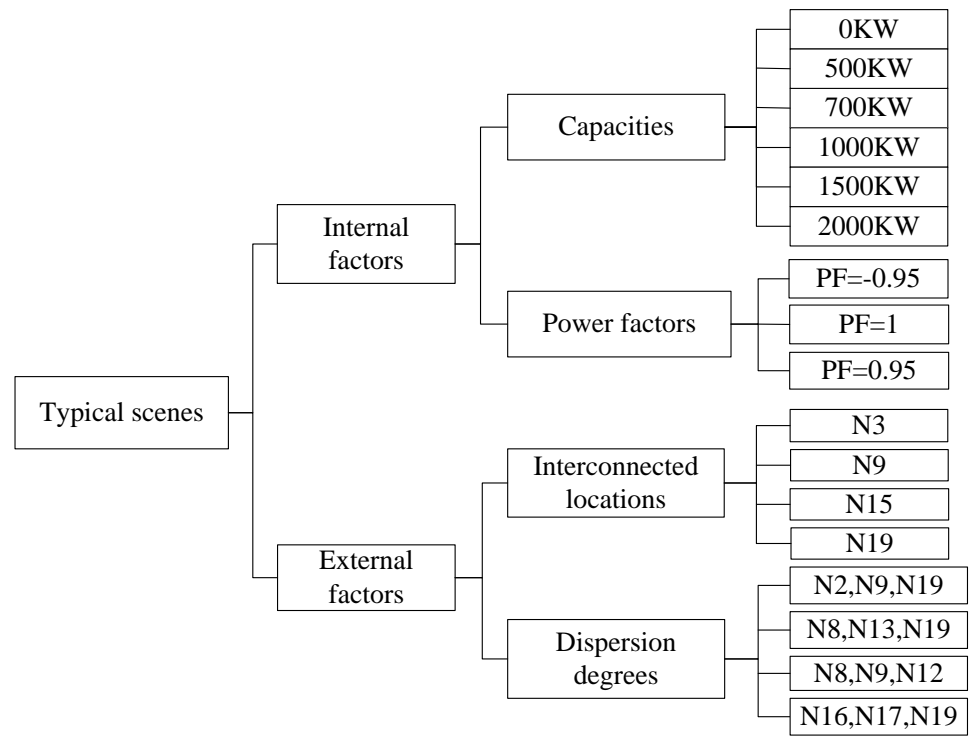

Figure 4. Typical scenes of PV accessed to the distribution network.

\section{Results and Discussion}

The distribution system is modeled and simulated by OpenDSS. The power flow of the distribution network and the assessment indices are calculated under different PV access conditions. Then the paper analyzes the impacts on static security of distribution network system with different grid-connected PV. The output power of PV system is affected greatly by irradiance, so the power flow and network losses at 12 o'clock are taken to calculate the normal operation ratio and network losses indices. The voltage fluctuation is a timing value.

\subsection{Effects of PV Capacity on Distribution Network Security}

Different capacities of PV are accessed to N19 in distribution network, set PF $=1$.

1) Normal Operating Ratio

As you can see from Figure 5, the capacity of PV system has big influence on normal operation rate of distribution network. The normal operation rate decreases with increasing PV capacity, it can meet more load demands. Then current becomes small and can reduce the line losses. But line L18 is connected with the PV access 
point, its normal operation rate becomes larger with the capacity increases, so the capacity of PV should not be too large to avoid the current of PV junction exceeds the normal allowable current.

2) Voltage Fluctuation Ratio

Figure 6 shows that the changes of voltage fluctuation rate are complex when PV system put into operation and break off from the network. The voltage enhances greatly and thus the fluctuation ratio increases when PV put into operation (around 7 a.m.). When PV out of operation (around 5 p.m.) and PV capacity is $1000 \mathrm{kw}$, the voltage fluctuation ratio reaches a minimum due to the voltage support of PV system. If the capacity continues to increase, the fluctuation ratio will deteriorate. At around 8 a.m. the system voltage varies greatly, the increment of capacity reduces the voltage obviously.

Comparing the data in Table 1, the capacity of PV is larger (no more than $1000 \mathrm{KW}$ ), the corresponding $\mathrm{E}_{\Delta \mathrm{V} \%}$ is smaller and the voltage fluctuation is improved. But when the capacity exceeds $1000 \mathrm{KW}$ (about $35 \%$ of the total power), $\mathrm{E}_{\Delta \mathrm{V} \%}$ and the voltage fluctuation will be larger with the capacity increases. Considering the voltage fluctuation of overall system, the capacity of PV should not more than the $35 \%$ of the total power.

3) Network losses

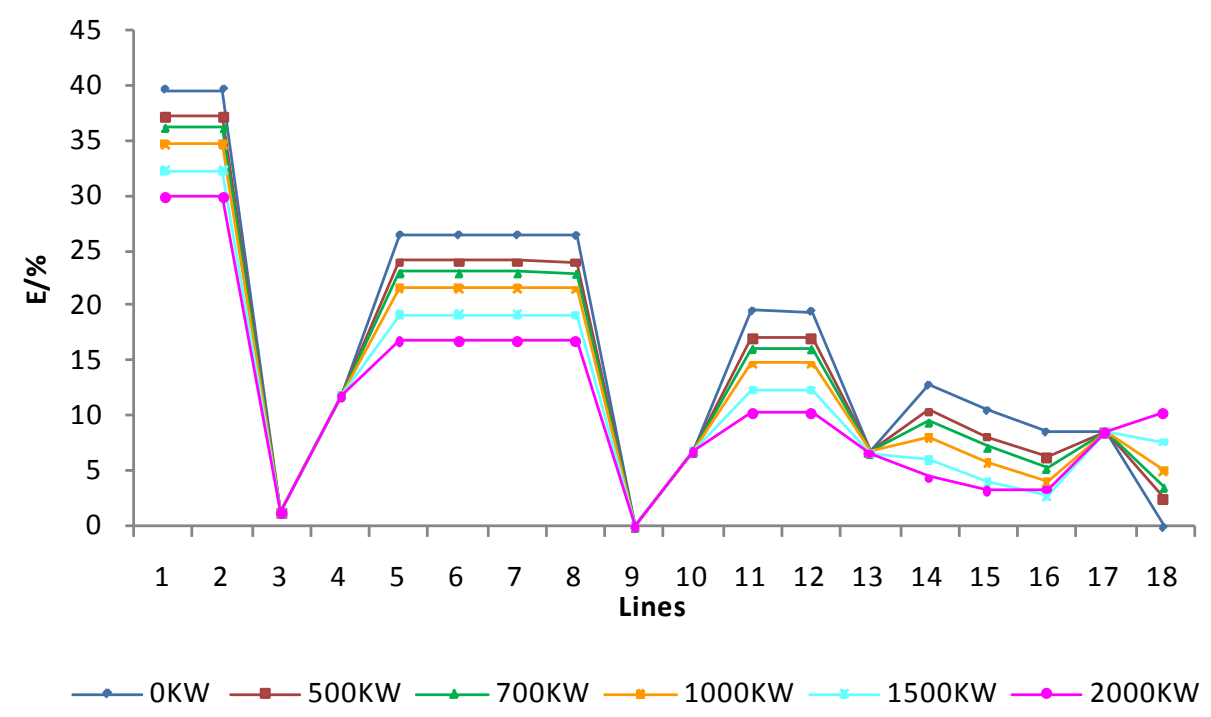

Figure 5. Normaloperating ratios under different PV capacities

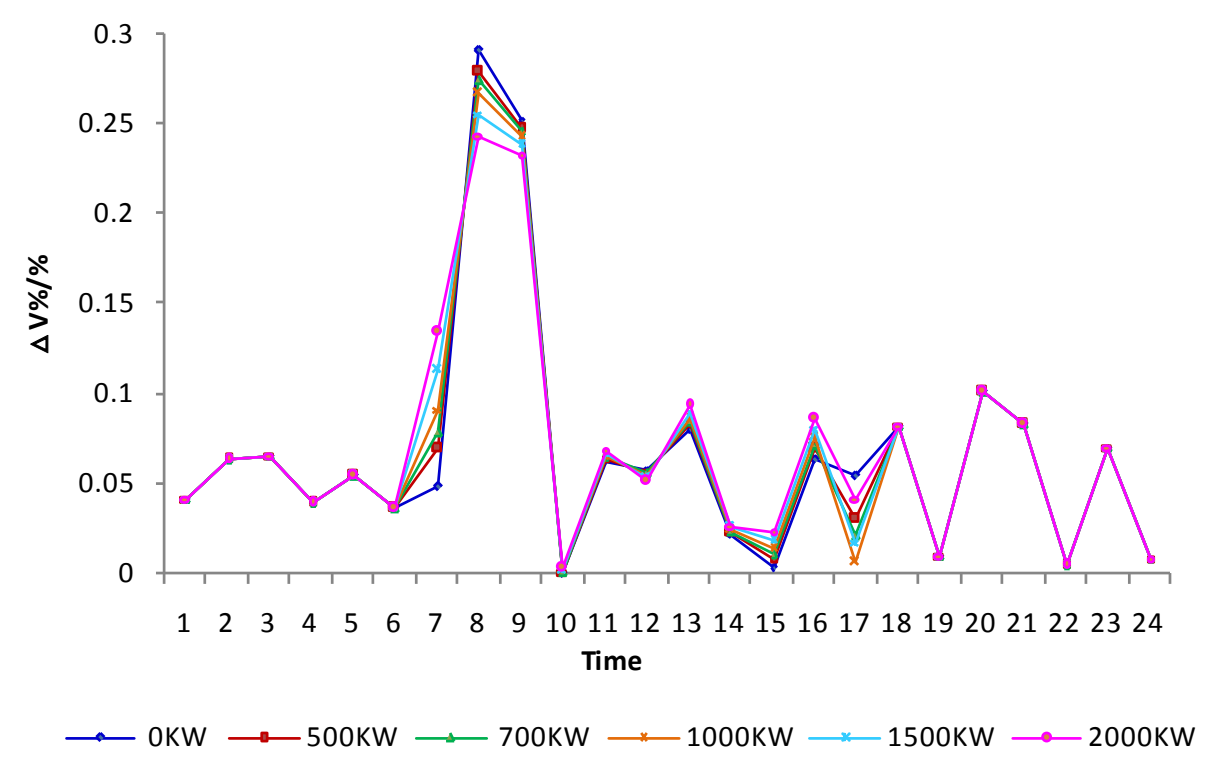

Figure 6. Voltage fluctuation ratios under different PV capacities. 
The grid-connected PV reduces the active power losses in a certain extent. The capacity is larger, the percentage of power losses is smaller, and the value of $\mathrm{M}$ is greater, the network losses got better improvement (Table 2).

\subsection{Effects of PV Locations on Distribution Network Security}

PV systems are accessed to the distribution network at N3, N9, N15 and N19. Set each PV capacity is $700 \mathrm{KW}$ and $\mathrm{PF}=1$.

1) Normal Operating Ratio

From Figure 7, distribution network is in normal operating condition under different PV interconnected locations, and the closer to the end of distribution network, the lower current becomes.

2) Voltage Fluctuation Ratio

From Figure 8, interconnected location of PV has small influences on voltage fluctuation of distribution network. Comparing the value of $E_{\Delta v} \%$, we will find that the closer to the end of the distribution network, the lower voltage fluctuation ratio is when PV capacity is appropriate (Table 3).

3) Network losses

As can be seen from Table 4, different interconnected locations have small effects on network losses. And the closer to the end of network, the lower $\mathrm{P}_{\text {loss }} \%$ is, and the value of $\mathrm{M}$ becomes higher at same time. It's indicates that network losses get a better improvement.

Table 1. Averages ofvoltage fluctuation ratiosunder different PV capacities.

\begin{tabular}{ccccccc}
\hline KW & 0 & 500 & 700 & 1000 & 1500 & 2000 \\
\hline $\mathrm{E}_{\Delta \mathrm{V} \%}$ & 0.06659 & 0.06645 & 0.06641 & 0.06632 & 0.06766 \\
\hline
\end{tabular}

Table 2. Network lossesunder different PV capacities.

\begin{tabular}{ccccccc}
\hline KW & 0 & 500 & 700 & 1000 & 1500 & 8.3 \\
$\mathrm{P}_{\text {loss }} / \mathrm{kW}$ & 13 & 11.4 & 10.7 & 9.7 & 0.1 \\
$\mathrm{P}_{\text {loss }} \%$ & $0.46 \%$ & $0.399 \%$ & $0.374 \%$ & $0.339 \%$ & $0.290 \%$ \\
$\mathrm{M}$ & 0 & 0.123 & 0.177 & 0.254 & 0.362 \\
\hline
\end{tabular}

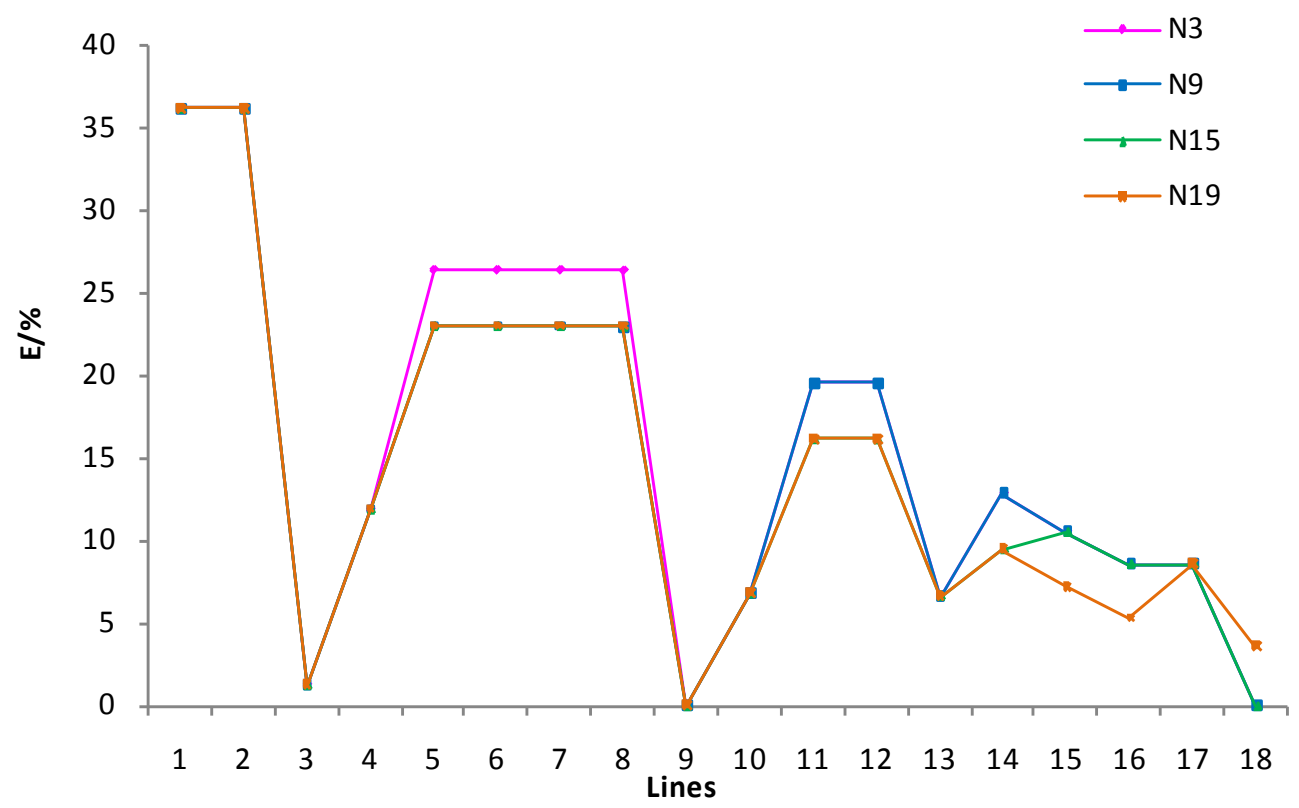

Figure 7. Normal operating ratios under different PV locations. 


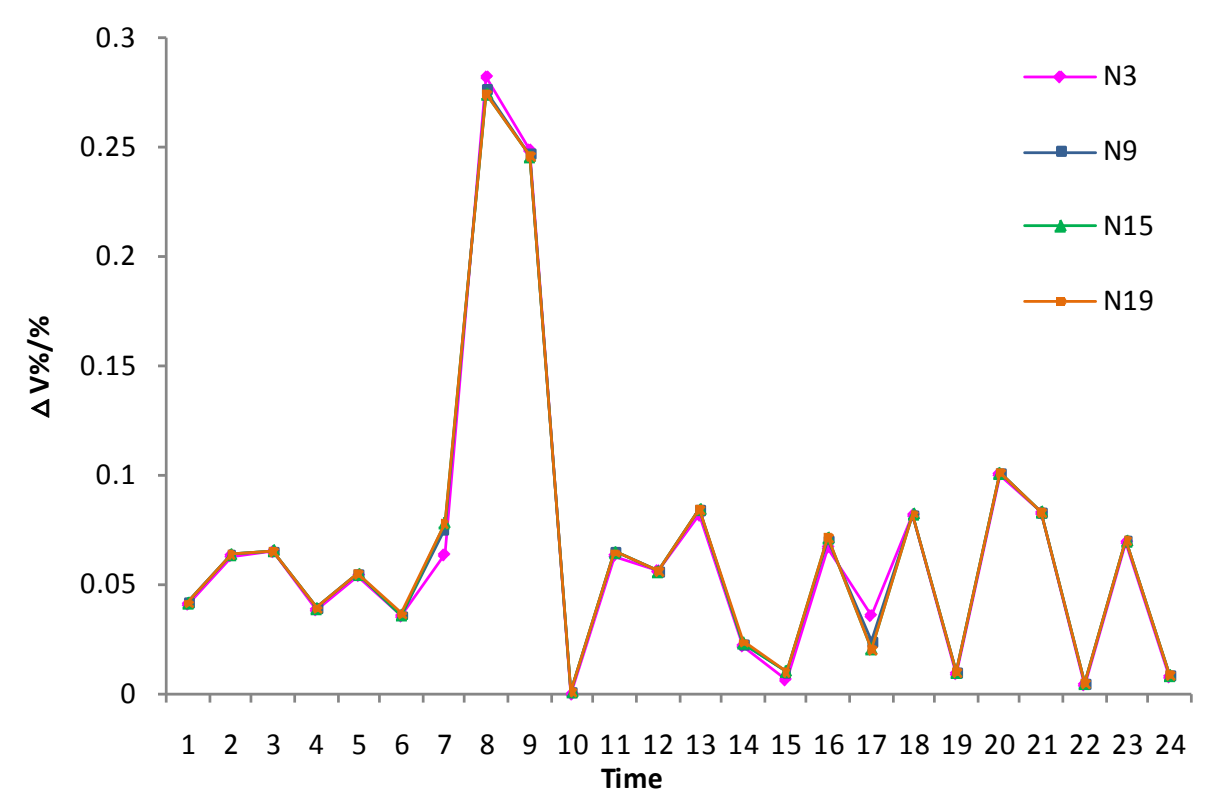

Figure 8. Voltagefluctuation ratiosunder different locations.

Table 3. Average of voltage fluctuation ratiosunder different locations.

\begin{tabular}{ccccc}
\hline Location & N3 & N9 & N15 & N19 \\
\hline $\mathrm{E}_{\Delta \mathrm{V} \%}$ & 0.06651 & 0.06644 & 0.06642 & 0.06641 \\
\hline
\end{tabular}

Table 4. Network lossesunder different locations.

\begin{tabular}{ccccc}
\hline Location & $N=3$ & $N=9$ & $N=15$ & $N=19$ \\
\hline$P_{\text {loss }} / \mathrm{kw}$ & 11.6 & 10.8 & 10.7 & 10.7 \\
$P_{\text {loss }} \%$ & $0.406 \%$ & $0.378 \%$ & $0.374 \%$ & $0.374 \%$ \\
$M$ & 0.108 & 0.169 & 0.177 & 0.177 \\
\hline
\end{tabular}

\subsection{Effects of PV Dispersion Degrees on Distribution Network Security}

Different combinations of PV are accessed to the distribution network, and each combination contains three PV systems. Set each PV capacity is $250 \mathrm{KW}$ and $\mathrm{PF}=1$. The combinations are show as below (Table 5).

The combination 1 of PV systems is evenly distributed in the distribution network. The combination 2 scattered in the terminal of network. The combination 3 is concentrated in the middle location, and the combination 4 is concentrated in terminal.

1) Normal Operating Ratio

As you can see from Figure 9, the normal operation rate E of combination 4 islowest, the value of combination 3 is highest. This can be seen that the influences of PV dispersion degrees on distribution network is minor, this mainly depends on the overall access location. When the distributed PV concentrated in the terminal of distribution network, the normal operation ratereaches the minimum, on the contrary, the $\mathrm{E}$ is the highest value when PV systems concentrated in the middle position (Table 6).

2) Voltage Fluctuation Ratio

The Figure 10 can be seen, the dispersion degree of distributed PV also shows small effects on voltage fluctuation of distribution network. Compare the average of voltage fluctuation ratio $E_{\Delta V}$, we can see that when PV systems scattered in the distribution network, the voltage fluctuation rate is larger. On the contrary, the $\mathrm{E}_{\Delta \mathrm{V} \%}$ reaches the minimum when PV systems concentrated in the terminal position and the voltage fluctuation ratio gets great improvement in this case. 
Table 5. Four combinations of distributed PV.

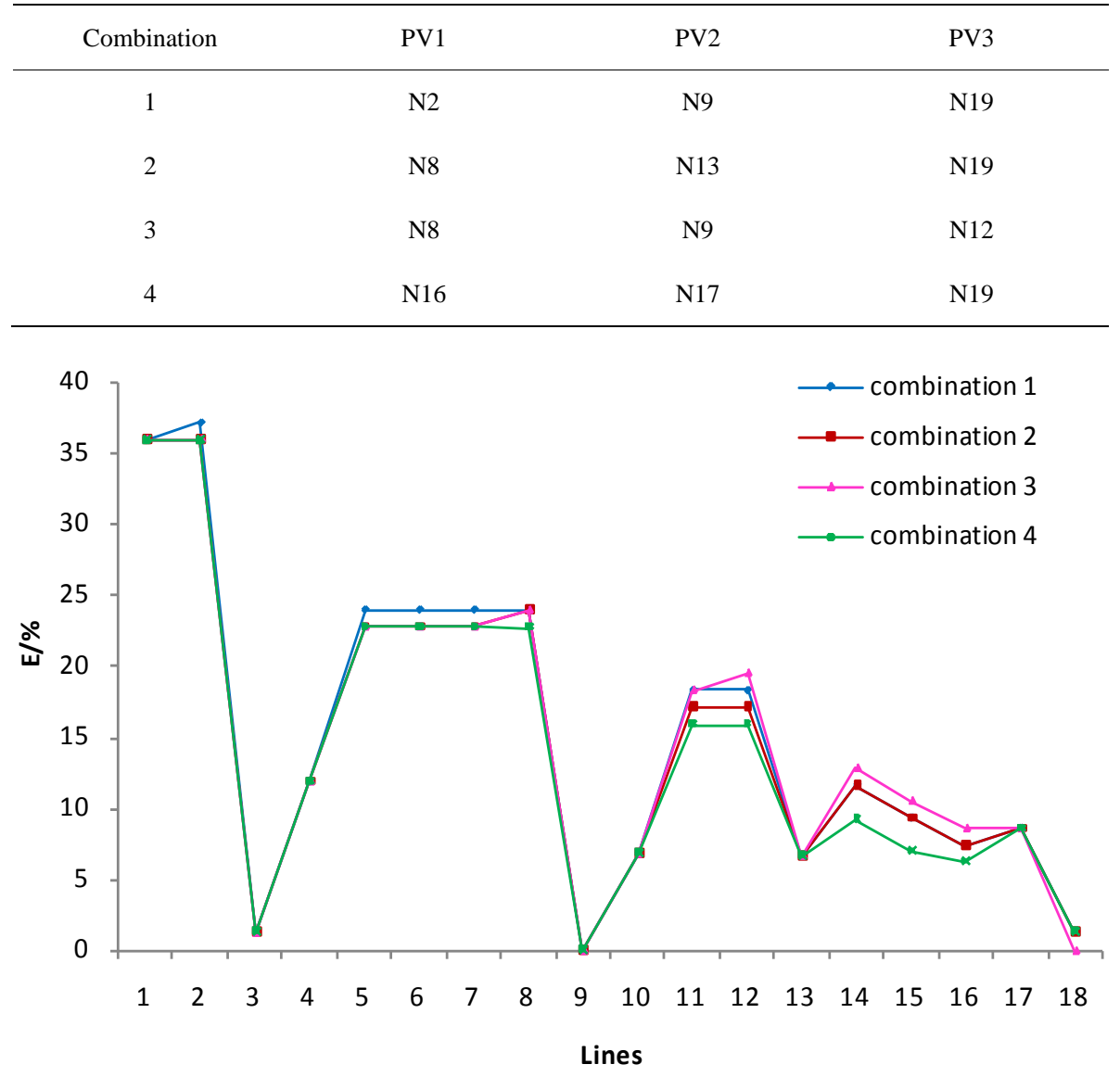

Figure 9. Normal operating ratios under different dispersion degrees.

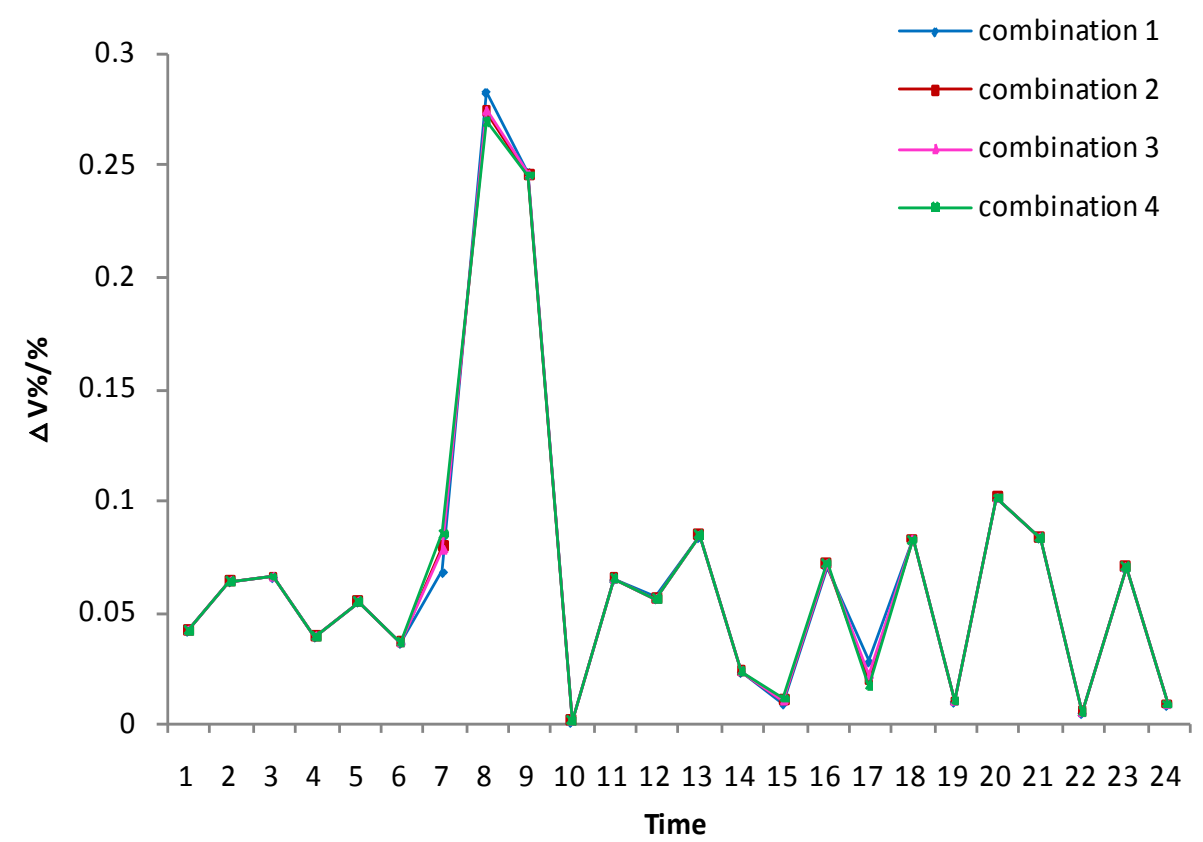

Figure 10. Voltage fluctuation ratios under different dispersion degrees. 
3) Network losses

As can be seen from Table 7, when distributed PV scatters in the distribution network, percentage of power losses is highest and the value of $\mathrm{M}$ is lowest, that indicates the improvement of network losses is smallest. Comparing the combination 2 with combination 3, we see that losses of combination 2 are lower. When PV systems concentrate in the end of network, percentage of power losses reaches the minimum and the value of $\mathrm{M}$ is highest, the network losses have a best improvement in this case.

\subsection{Effects of PV Power Factors on Distribution Network Security}

Different power factors of PV systems with the capacity of $700 \mathrm{~kW}$ are accessed to the N19 separately. PF $<0$ represents the PV system operates in the state that PV absorbs reactive power, PF $>0$ represents the PV system provides reactive power.

1) Normal Operating Ratio

Figure 11 shows that the power factors of PV have slight impacts on the normal operation ratio. The normal operation ratio reaches the minimum when PV provides reactive power and equals 0.95 . On the contrary, the normal operation ratio reaches the maximum when PV absorbs reactive power and equals -0.95 .

2) Voltage Fluctuation Ratio

Compare Figure 12 and $\mathrm{E}_{\Delta \mathrm{V} \%}$, we can see that the voltage fluctuation ratio is highest when $\mathrm{PF}<0$. When $\mathrm{PF}>$ 0 , the voltage fluctuation ratio is lowest and has minimal impacts on the stable operation of the distribution network in this case (Table 8).

3) Network losses

Table 6. Average of voltage fluctuation ratios under different dispersion degrees.

\begin{tabular}{ccccc}
\hline Combination & 1 & 2 & 3 & 4 \\
$\mathrm{E}_{\Delta \mathrm{V} \%}$ & 0.066438 & 0.066408 & 0.066408 & 0.066394 \\
\hline
\end{tabular}

Table 7. Network losses under different dispersion degrees.

\begin{tabular}{ccccc}
\hline Combination & 1 & 2 & 3 & 4 \\
\hline $\mathrm{P}_{\text {loss }} / \mathrm{kw}$ & 11.0 & 10.6 & 10.7 & 10.5 \\
$\mathrm{P}_{\text {loss }} \%$ & $0.383 \%$ & $0.371 \%$ & $0.374 \%$ & $0.367 \%$ \\
$\mathrm{M}$ & 0.154 & 0.185 & 0.177 & 0.192 \\
\hline
\end{tabular}

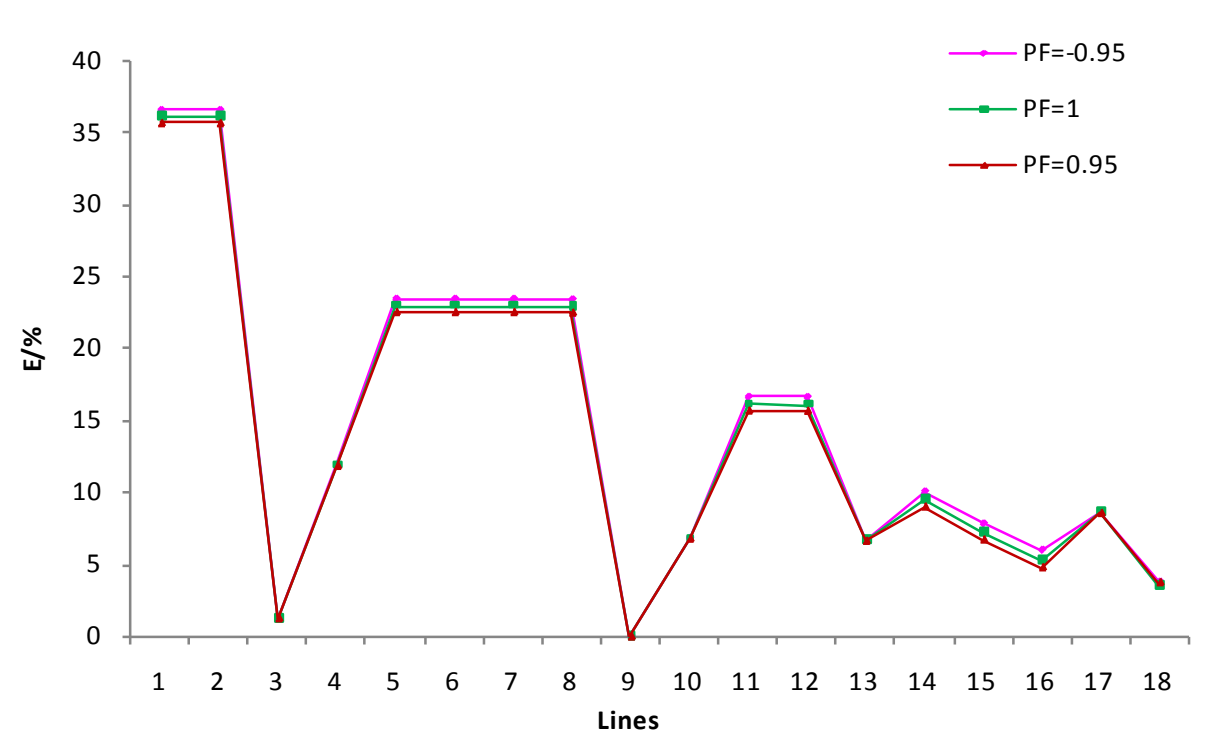

Figure 11. Normal operating ratios under different power factors. 


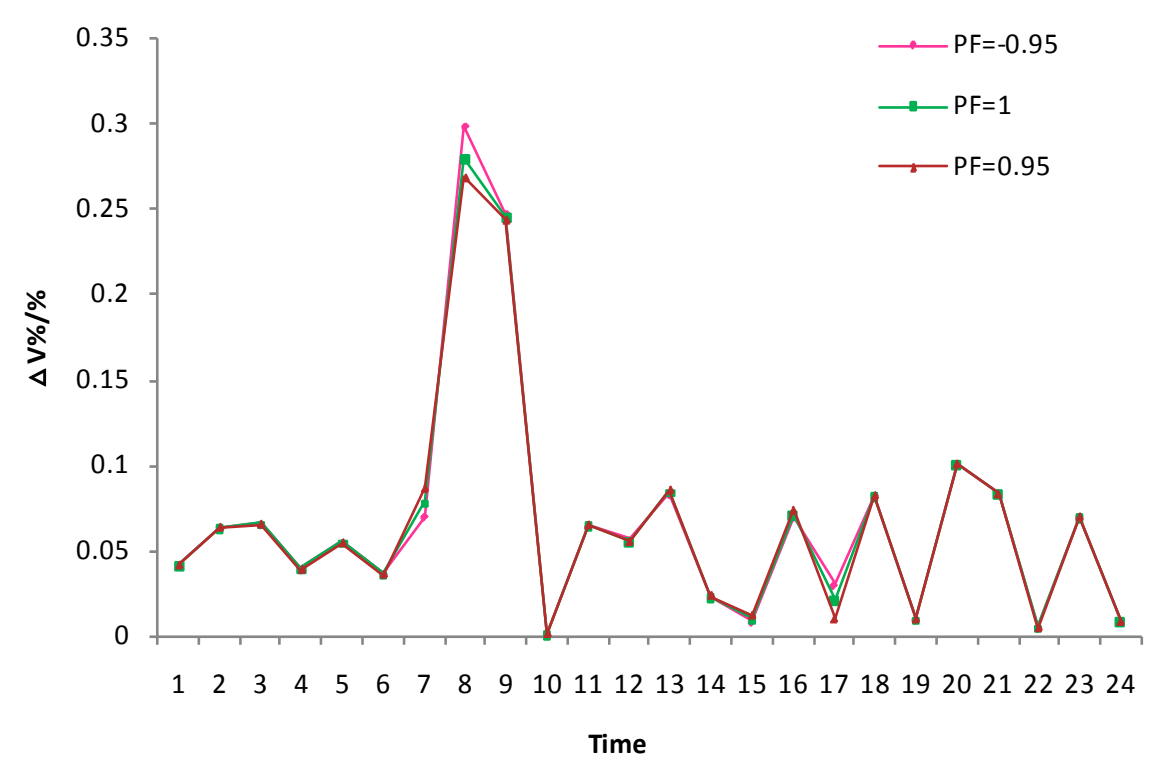

Figure 12. Voltage Fluctuation ratios under different PV power factors.

Table 8. Average of voltage fluctuation ratios under different PV power factors.

\begin{tabular}{cccc}
\hline $\mathrm{PF}$ & -0.95 & 1 & 0.95 \\
\hline $\mathrm{E}_{\Delta \mathrm{V} \%}$ & 0.06647 & 0.06641 & 0.06638 \\
\hline
\end{tabular}

Table 9. Network losses under different power factors.

\begin{tabular}{cccc}
\hline PF & -0.95 & 1 & 0.95 \\
\hline $\mathrm{P}_{\text {loss }} / \mathrm{kw}$ & 11.0 & 10.7 & 10.4 \\
$\mathrm{P}_{\text {loss }} \%$ & $0.383 \%$ & $0.374 \%$ & $0.364 \%$ \\
$\mathrm{M}$ & 0.154 & 0.177 & 0.2 \\
\hline
\end{tabular}

When $\mathrm{PF}<0$, the reactive power is absorbed, percentage of power loss reaches the maximum, and the value of $\mathrm{M}$ is lowest, the network losses have the smallest improvement. On the contrary, when PF is running the condition that provides the reactive power, $\mathrm{P}_{\text {loss }} \%$ is lowest and the value of $\mathrm{M}$ is highest, the network losses have a great improvement (Table 9).

\section{Conclusions}

1) On the premise of determining the interconnected location of PV, the PV permeability has a significant impact on the normal operation ratio, fluctuation ratio and network losses of distribution network. When the capacity of grid-connected PV is larger(less than 35\% of the total power), the normal operation ratio E of distribution system is smaller and the feeder current will not exceed the normal allowable current generally, and the system can meet more load demands in this case. Meanwhile, the overall voltage fluctuation ratio will decrease and the network losses will get a great improvement. However, if the PV capacity exceeds 35\% of the total power, not only is it easy to cause the system voltage exceeds the limit, but also the voltage fluctuation ratio and network losses will increase. So the PV capacity should less than 35\% of the total power.

2) When the capacity of grid-connected PV is appropriate, the interconnected location of PV has a slight impact on the distribution network. The normal operation ratio E will be smaller when PV accesses to the end terminal, meanwhile the voltage fluctuation ratio will getaimprovement and the network losses will decrease. Considering the risk of over voltage, the PV should be chose to access to the position that is near to the end of the distribution network. 
3) When multiple PV systems are accessed to the distribution system, the dispersion degrees have a slight effect on the distribution network which mainly depends on whether the overall locations of PV systems are near to the end of the system. When the distributed PV systems are accessed to the distribution network dispersedly, the normal operation ratio and voltage fluctuation ratio is high, meanwhile, the network losses will get a small improvement. On the contrary, the normal operation ratio is low when the distributed PV systems concentrate in the end of distribution network, thus the network can meet more load demands and the voltage fluctuation ratio will also decrease, the network losses have a great improvement.

4) Be sure that PV systems are accessed to the distribution network in an appropriate capacity and location, the normal operation ratio $\mathrm{E}$ of distribution network system is low and the feeder current will not exceed the normal allowable current generally when PF $>0$ and PV provides reactive power. Meanwhile the voltage fluctuation ratio decreases and the network losses of distribution network get a great improvement.

The paper only analyzes the static security of distribution system with the distributed PV. The research on transient security will be discussed later.

\section{References}

[1] Xie, H.H. and Mao, J.L. (2011) Research on Security Indices and Method of Distribution Networks. Electric Power Technology, 10, 39-41.

[2] Liu, R.X., Zhang, J.H. and Wu, D. (2011) Research on Static Security Index of Distribution Network Based on Risk Theory. Power System Protection and Control, 39, 89-95.

[3] Xu, X.Y., Huang, Y.H., Liu, C. and Wang, W.S. (2010) Influence of Distributed Photovoltaic Generation on Voltage in Distribution Network and Solution of Voltage beyond Limits. Power System Technology, 34, 140-146.

[4] Fan, Y.L., Zhao, B., Wang, Q.Y. and Cao, Y.J. (2012) Peak Capacity Calculation of Distributed Photovoltaic Source with Constraint of Over-Voltage. Automation of Electric Power Systems, 36, 40-44.

[5] Dai, W.Z. (2011) Power System Security and Its Prevention. Electrical Engineering, 12, 85-89.

[6] Huang, X.K., Wang, H., Wang, Y.B. and Xu, H.H. (2014) Principle and Strategies of Voltage Rise Regulation for Grid-Connected Photovoltaic Generation System at Point of Common Coupling. Automation of Electric Power Systems, 38, 112-117.

[7] He, H.Y., He, H.Q. and Li, X.S. (2014) Analysis on Effect of Distribution Photovoltaic Grid-Connection on Grid Network Loss. Modern Electronics Technique, 37, 158-162.

[8] Shi, Z.G. (2010) Research of Impact of Grid-Connected Photovoltaic Power Generation System on Distribution Network. Master's Thesis, North China Electric Power University, Beijing.

[9] Xiao, Y.H., Yao, J.G. and Zhang, J. (2009) Analysis on Power Grid Safety Assessment System. Power System Technology, 33, 77-82.

[10] Wu, X.L. (2013) Impacts of Grid-Connected Photovoltaic Generation on Distribution System. Master's Thesis, Hefei University of Technology, Hefei.

[11] Nie, S. (2012) Analysis and Reconfiguration of Smart Distribution Network with Distributed Generation. Master's Thesis, Tianjin University, Tianjin. 